\title{
Effect of swirl flow on the performance of parallel hub axial annular diffuser
}

\author{
Hardial Singh and B.B.Arora* \\ Department of Mechanical Engineering, Delhi Technological University, Delhi, India \\ * Corresponding Author: bbarora@dce.ac.in
}

Submitted :07/02/2020

Revised : $30 / 12 / 2020$

Accepted : 26/01/2021

\begin{abstract}
In the present work, the parallel hub axial flow annular diffuser's performance characteristics with divergent casing varying between equivalent cone angle $\left(10^{\circ}, 15^{\circ}\right.$, and $\left.20^{\circ}\right)$ with area ratio 3 have been evaluated computationally as well as experimentally. The performance of three diffusers was tested at different inlet swirl angles (from $0^{\circ}$ to $25^{\circ}$ ) for swirling and nonswirling flow. Simulations have been carried out on a fully developed flow at Reynolds number $2.5 \times 10^{5}$. The results were analyzed based on the velocity profiles, static pressure recovery coefficient, and the total pressure loss coefficient. The result analysis shows that the inlet swirl flow improves the recovery of pressure and also delays the flow separation on the casing. Moreover, the findings also show that the best performance was achieved in equivalent cone angle $10^{\circ}$ at the inlet swirl angle of $7.5^{\circ}$ compared to other diffusers.
\end{abstract}

Keywords: Annular diffuser; Static pressure recovery coefficient; Total pressure loss coefficient; Inlet swirl angle.

\section{NOMENCLATURE}

\begin{tabular}{llll}
$\theta$ & Divergence angle of wall, deg; & \multicolumn{2}{l}{ Subscripts } \\
$\Delta \mathrm{R}$ & Annulus height, $\mathrm{cm} ;$ & $\mathrm{c}$ & Casing; \\
$\mathrm{L}$ & Length of diffuser, cm; & $\mathrm{h}$ & hub; \\
$\mathrm{x} / \mathrm{L}$ & Non-dimensional axial length; & $\mathrm{i}$ & Inlet; \\
$\mathrm{y} / \mathrm{Ym}$ & Non-dimensional radial length. & o & Outlet; \\
& & $\mathrm{e}$ & Equivalent.
\end{tabular}

\section{INTRODUCTION}

The annular diffuser is a mechanical flow diffusing device that is used for many engineering applications. The diffuser's primary function is to recuperate the static pressure due to reducing the flow's mean velocity. The annular diffuser is mainly used in the pump, compressor, gas turbine engine, turbomachinery, etc. (Kline, 1959). The fluid flow around the bearing, vanes, and strut creates a swirl effect at the diffuser's entry. The swirl effect at the inlet is 
one way to increase the overall performance of the diffuser. Reneau et al. (1967) experimentally examined the effect of flow characteristics on two-dimensional straight wall diffusers. It was found that diffuser performance decreases as the inlet blockage increases in the two-dimensional conical diffusers. Coladipietro (1974) studied the inlet swirl and boundary layer thickness effect on the performance of diffusers. The efficiency and pressure recovery coefficient were more pronounced in a thin boundary layer for a small nondimensional length. Adenubi (1976) experimentally studied the flow regimes of straight core annular diffuser with downstream turbo machine inlet conditions. It was observed that the annular diffuser's effectiveness is enhanced by increasing the turbulence level at the inlet. Singh et al. (1994) found that swirl improved the recovery of pressure and suppressed the separation of flow on the casing in the wide-angle annular diffuser. Mohan et al. (1998) analyzed the optimum performance of the diffusers with the computational approach with less cost than the experimentation. It shows that maximum pressure recovery improvement is achieved at a $17.5^{\circ}$ diffuser. Shuja and Habib (1996) studied the axisymmetric annular diffuser and concluded that the increase in the flow region's heat transfer coefficient depends on the cant angle. They have also shown that the Nusselt number is a function of the Reynolds number. Ubertini and Desideri (2000) described the gas turbine annular exhaust diffuser with and without strut as having effectiveness 15 percent and less than 15 percent, respectively. It is shown that overall diffuser losses were enhanced in the axial region of a strut. Arora and Pathak (2009); Arora et al. (2010); Arora (2014); Singh and Arora (2019) carried out the experimental and numerical investigation of geometrical parameters on the annular diffuser with swirl flow. They concluded that the recovery of static pressure is faster with the introduction of swirl at the diffuser's entry.

Very little research work has been carried out experimentally on the swirl flow in annular diffusers. Based on the exhaustive literature review, it is very difficult to conclude which choice of geometric parameters and dynamic parameters will give diffusers the desirable performance because the fluid flow is quite complicated. Since there is no research work carried out on the different cone angles and has the same area ratio, it needs to be explored. The main work is focused on the parallel hub axial annular diffuser with varying geometries but having the same area ratio 3. The effect of swirl intensity is analyzed with different swirl regimes on the flow characteristics of annular diffusers. Further, the prediction of the flow separation and reattachment of the flow are carried out inside the annular diffusers. Figure 1 and Table 1 show the geometrical configuration details of the parallel hub axial annular diffuser parameters.

Table 1. Geometrical parameters of parallel hub axial annular diffusers.

\begin{tabular}{|c|c|c|c|c|}
\hline \multicolumn{5}{|c|}{$\mathrm{R}_{\mathrm{hi}}=3.8 \mathrm{~cm}, \mathrm{R}_{\mathrm{ci}}=7.75 \mathrm{~cm}, \theta_{\mathrm{h}}=0(\mathrm{deg}), \mathrm{AR}=3$} \\
\hline Sr. No. & $\boldsymbol{\theta}_{\mathrm{c}}(\mathbf{d e g})$ & $\mathbf{L}(\mathbf{c m})$ & $\mathbf{L} / \mathbf{R}$ & $\boldsymbol{\theta}_{\mathrm{e}}(\mathbf{d e g})$ \\
\hline A & 4.6 & 56.51 & 14.30 & 10 \\
\hline B & 6.91 & 37.55 & 9.50 & 15 \\
\hline C & 9.22 & 28.04 & 7.09 & 20 \\
\hline
\end{tabular}




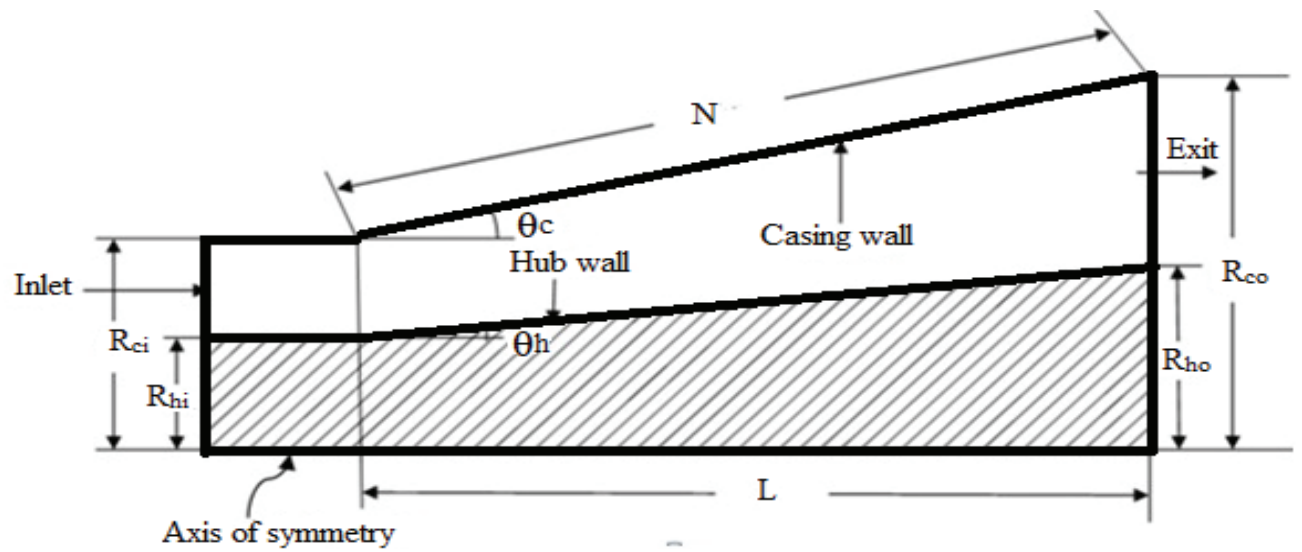

Figure 1. Diffuser geometrical parameter.

\section{EXPERIMENTAL SETUP}

Figure 2 (i) shows the annular diffuser experimental setup used for experimentation. Figure 2 (ii) represents the setup's main components, i.e., blower, settling chamber, swirl plate, annular passage, and diffuser. The centrifugal blower sucks air from the ambiance and then delivers it to the settling chamber with a conical divergence section, which is precisely aligned with the settling chamber. The airflow rate is controlled by changing the rpm of the impeller and throttling valve placed at the inlet. The settling chamber consists of a honeycomb and different mesh screen sizes to prevent the flow fluctuation, reduce turbulence, and make the flow uniform. A well designed conical contraction zone of settling chamber is connected to the long annulus passage in which flow commences. The swirl plate is located upstream of the test diffuser to avoid the wake effect at the test diffuser's entry to recover the pressure. Test diffuser made of transparent Perspex and hub casted of aluminum material, which is perfectly machined to get a smooth surface fabricated with a precision of \pm 1 percent tolerance. The numbers of static pressure taps on the casing and hub wall are made along the test diffuser's length to measure static pressure with manometers. The manometers are inclined at an angle of $10^{\circ}$ with the horizontal to increase the sensitivity of reading. The longitudinal velocity and swirl velocity are measured along with the test diffuser's axial locations using a three-hole cobra probe using the null technique (Bryer and Pankhurst, 1971). The cobra probe yaw angle is set to zero by aligning with the incoming flow in this technique. The calibration range is associated with the cobra probe to measure the velocity within $\pm 55 \mathrm{deg}$. The manometer's uncertainty for measurement of the static pressure is $\pm 1.5 \mathrm{~mm}$ of water, and the total pressure is $\pm 1 \mathrm{~mm}$ of water.

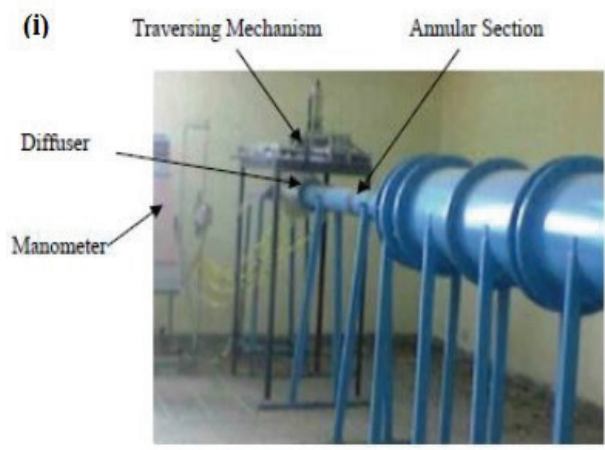

(ii)

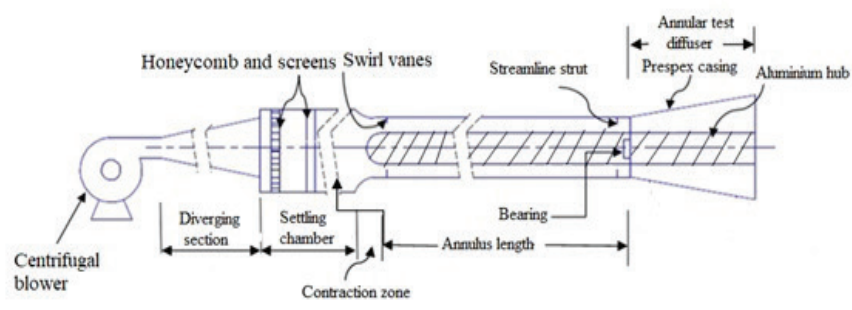

Figure 2. (i) Experimental setup. (ii) Schematic of the experimental setup. 


\section{MATHEMATICAL FORMULATIONS}

The equation of continuity in $2 \mathrm{D}$ axisymmetric geometry is given as

$$
\frac{\partial}{\partial x}\left(\rho v_{x}\right)+\frac{\partial}{\partial r}\left(\rho v_{r}\right)+\frac{\rho v_{r}}{r}=s_{m}
$$

where $v_{\mathrm{x}}$ is the axial direction velocity, and $v_{r}$ is the radial direction velocity. $S_{m}$ is the mass added to the continuous phase from the dispersed phase.

The governing equations of momentum conservation for steady axisymmetric nonswirling flow in the axial and radial directions are given as

$$
\begin{aligned}
& \frac{1}{r} \frac{\partial}{\partial x}\left(r \rho v_{x} v_{x}\right)+\frac{1}{r} \frac{\partial}{\partial r}\left(r \rho v_{r} v_{x}\right)= \\
& -\frac{\partial p}{\partial x}+\frac{1}{r} \frac{\partial}{\partial x}\left[r \mu\left(2 \frac{\partial v_{x}}{\partial x}-\frac{2}{3}(\nabla \cdot v)\right)\right]+\frac{1}{r} \frac{\partial}{\partial r}\left[r \mu\left(\frac{\partial v_{x}}{\partial r}+\frac{\partial v_{r}}{\partial x}\right)\right]+F_{x}
\end{aligned}
$$

\section{And}

$$
\begin{aligned}
& \frac{1}{r} \frac{\partial}{\partial x}\left(r \rho v_{x} v_{r}\right)+\frac{1}{r} \frac{\partial}{\partial r}\left(r \rho v_{r} v_{r}\right)= \\
& -\frac{\partial p}{\partial r}+\frac{1}{r} \frac{\partial}{\partial x}\left[r \mu+\left(\frac{\partial v_{r}}{\partial x}+\frac{\partial v_{x}}{\partial r}\right)\right]+\frac{1}{r} \frac{\partial}{\partial r}\left[r \mu\left(2 \frac{\partial v_{r}}{\partial r}-\frac{2}{3}(\nabla \cdot v)\right)\right] \\
& -2 \mu \frac{v_{r}}{r^{2}}+\frac{2}{3} \frac{\mu}{r}(\nabla \cdot v)+\rho \frac{v_{z}^{2}}{r}+F_{r}
\end{aligned}
$$

where

$$
\nabla \cdot v=\frac{\partial v_{x}}{\partial x}+\frac{\partial v_{r}}{\partial r}+\frac{v_{r}}{r}
$$

Here, $F_{x}$ and $F_{r}$ represent axial and radial forces, respectively.

The tangential momentum equation for swirling flows needs to be solved, which can be written as 


$$
\begin{aligned}
& \frac{1}{r} \frac{\partial}{\partial x}\left(r \rho v_{x} v_{z}\right)+\frac{1}{r} \frac{\partial}{\partial r}\left(r \rho v_{r} v_{z}\right)= \\
& \frac{1}{r} \frac{\partial}{\partial x}\left[r \mu \frac{\partial v_{z}}{\partial x}\right]+\frac{1}{r^{2}} \frac{\partial}{\partial r}\left[r^{3} \mu \frac{\partial}{\partial r}\left(\frac{v_{z}}{r}\right)\right]-\rho \frac{v_{r} v_{z}}{r}
\end{aligned}
$$

where $v_{z}$ represents the swirl velocity.

The turbulent flow parameters are computed, and turbulence models are analyzed to the close solution of the RANS set of equations (1-5). The selection of turbulence models such as $\mathrm{k}-\varepsilon$ standard, $\mathrm{k}-\omega$ standard, $\mathrm{k}-\varepsilon$ Realizable, $\mathrm{k}-\varepsilon$ RNG, and $\mathrm{k}-\omega \mathrm{SST}$ on the annular diffuser with swirl flow is a complicated process. The RNG k- $\varepsilon$ turbulence model is a more advanced model as compared to the $\mathrm{k}-\varepsilon$ standard model.

Mohan et al. (1998); Singh et al. (2006); Arora and Pathak (2009); Arora et al. (2010) have adopted two-equation turbulence model k- $\varepsilon$ RNG on annular diffusers for their work, while work using k- $\varepsilon$ Standard model was carried out by Sadasivan et al. (2019). The result from the simulation of a nondimensional longitudinal velocity profile distribution at $\mathrm{x} / \mathrm{L}=0.7$ is shown in Figure 3. It is seen that the $\mathrm{k}-\varepsilon \mathrm{RNG}$ turbulence model gives the lowest average deviation as compared to the experimental results. Hence, $\mathrm{k}-\varepsilon \mathrm{RNG}$ turbulence model is employed for simulation in the present study.

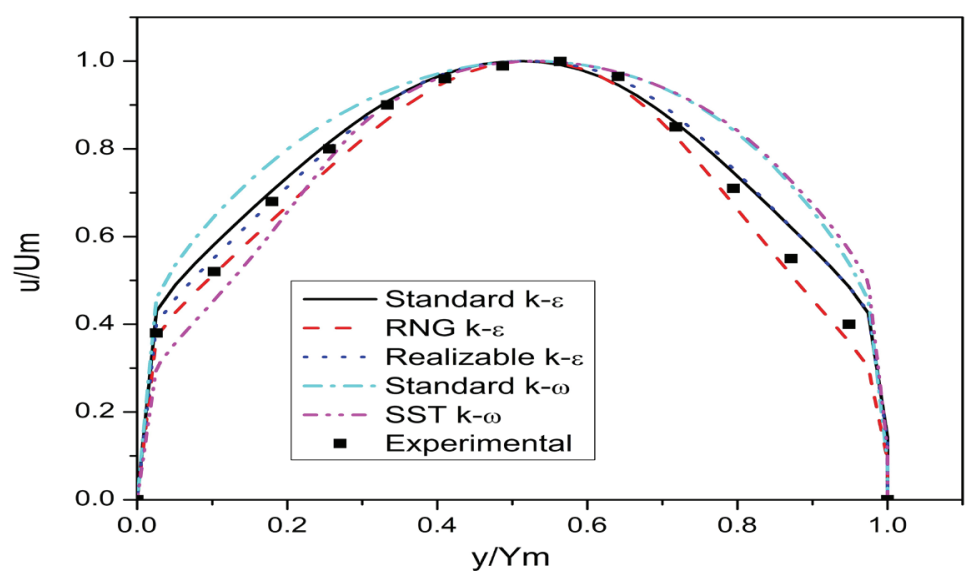

Figure 3. Comparison of the turbulence models with the experimental results of the longitudinal velocity profile at $\mathrm{x} / \mathrm{L}=0.7$ of equivalent cone angle $10^{\circ}$.

\section{COMPUTATIONAL DOMAIN AND BOUNDARY CONDITIONS}

An axis-symmetric two-dimensional computational domain of the annular diffuser has been sketched in the ANSYS Fluent v16.2 software. A map meshing scheme has been used with a quadrilateral element to carry out the simulations. The 2D mesh geometry of the computational domain has been shown in Figure 4. Very fine mesh is placed near the wall by maintaining the $y+<1$. The first node of the mesh is placed at a distance of $0.02 \mathrm{~mm}$ from the wall to predict the velocity gradient near the wall. The quality of the mesh is maintained in terms of skewness, aspect ratio, and orthogonality. The inlet velocity profile is fed in the axisymmetric diffuser similar to the velocity profile obtained from the experimental setup. The turbulent intensity $3 \%$ is applied at the inlet, and the value of the hydraulic diameter is calculated as per the diffuser's geometry. The boundary conditions at the outlet are applied $3 \%$ turbulent 
intensity normal to the boundary, zero gauge pressure, and thus calculated value of the hydraulic diameter $\left(\mathrm{h}_{\mathrm{d}}\right)$ from the geometry of diffuser. The $2^{\text {nd }}$ order upwind scheme is used to control the solution for swirl velocity, momentum, turbulent kinetic energy $(\mathrm{k})$, and turbulent dissipation rate $(\omega)$ for better accuracy of results. The employed residuals for convergence criteria are $10^{-6}$ to achieve convergence solution by an iteration method. The SIMPLE algorithm method is used for the stability of the solution.

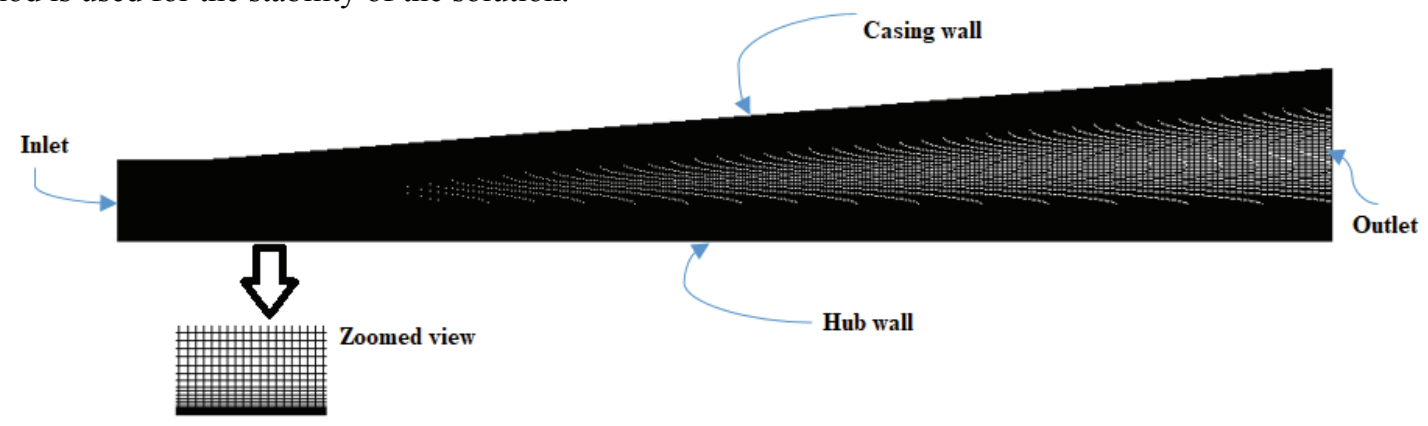

Figure 4. 2D axisymmetric computational domain with meshing.

\section{GRID INDEPENDENCE TEST}

In the current work, a grid test is carried out to obtain mesh independence results. The different diffusers having various geometrical designs will have different grid sizes depending upon the geometrical dimension.

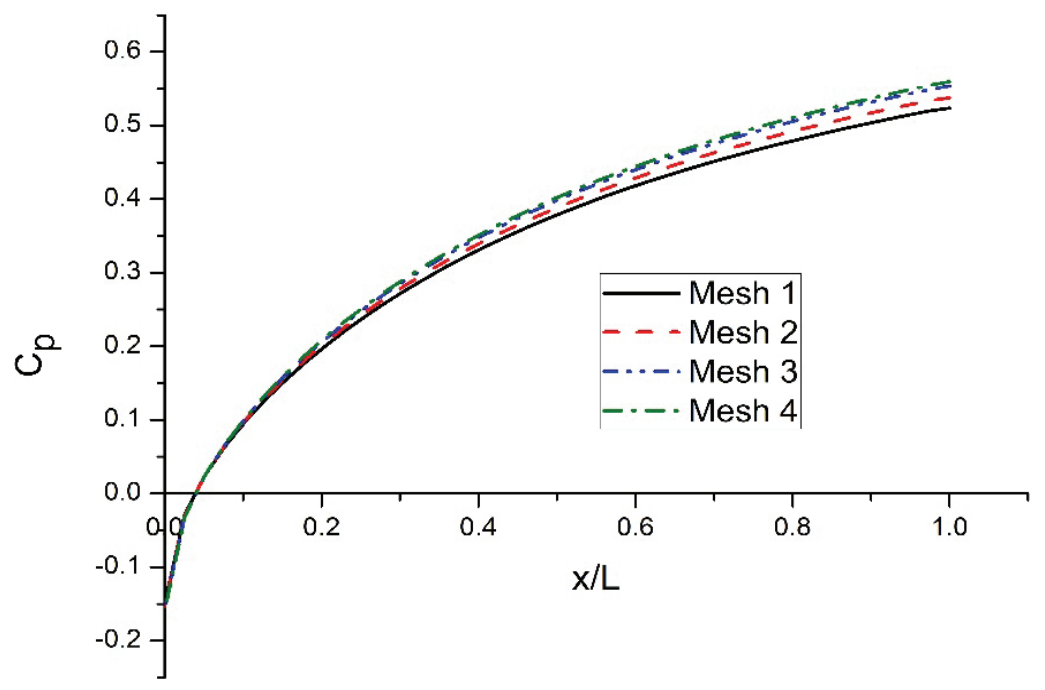

Figure 5. Pressure recovery coefficient at casing wall comparison for four mesh sizes.

The parallel hub axial annular diffusers having an equivalent cone angle $10^{\circ}$ with area ratio 3 of four grid sizes (mesh $1=90000$, mesh $2=120000$, mesh $3=160000$, and mesh $4=190000$ ) were tested at Reynolds number $2.5 \times 10^{5}$ using k- $\varepsilon$ RNG turbulence model for swirl flow. Pressure coefficient profiles for Mesh 3 and Mesh 4 are very close to each other, and hence, cell count of Mesh 3 is selected for the current study, as shown in Figure 5. The simulation is performed on the i5 processor with $8 \mathrm{~GB}$ RAM, and the time required to solve the simulation of 160000 elements is $18 \mathrm{hrs}$. 


\section{RESULTS AND DISCUSSION}

The computationally determined velocity vectors, longitudinal velocity profiles, swirl velocity profiles, static pressure recovery coefficient $\left(\mathrm{C}_{\mathrm{p}}\right)$, and total pressure loss coefficient $\left(\mathrm{C}_{\mathrm{TL}}\right)$ across the diffuser's length are presented and discussed.

\section{Velocity Vector}

The axisymmetric 2D annular diffusers (A, B, and C) with and without swirl flow of velocity vectors at the inlet swirl angles $\left(0^{\circ}, 12^{\circ}\right.$, and $\left.25^{\circ}\right)$ are shown in Figure. 6 . The velocity vectors show the result across the length, i.e., inlet, $\mathrm{x} / \mathrm{L}=0.1,0.3,0.5,0.7,0.9$, and outlet using CFD.
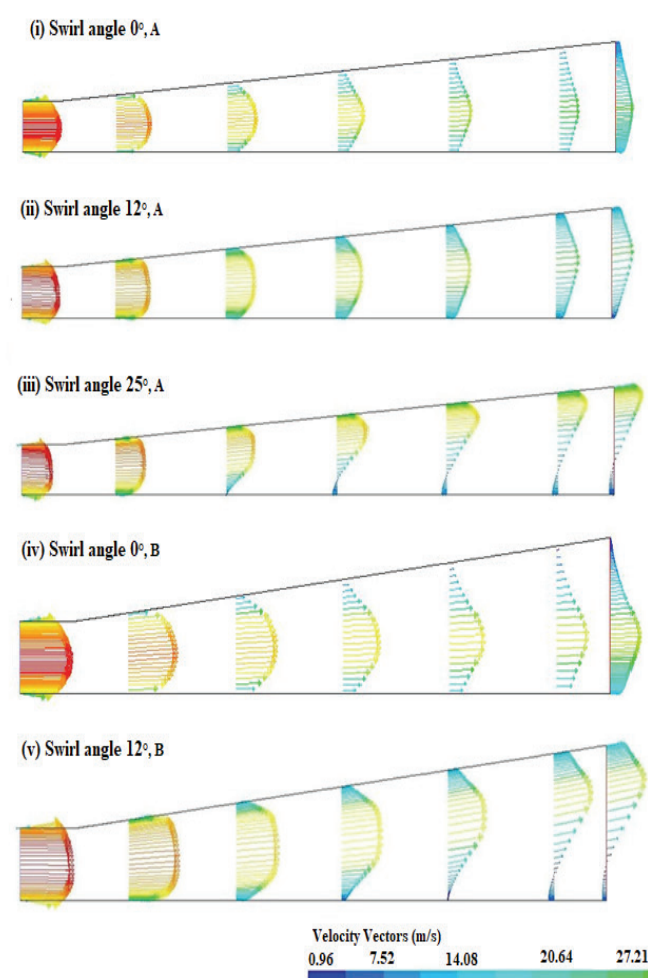
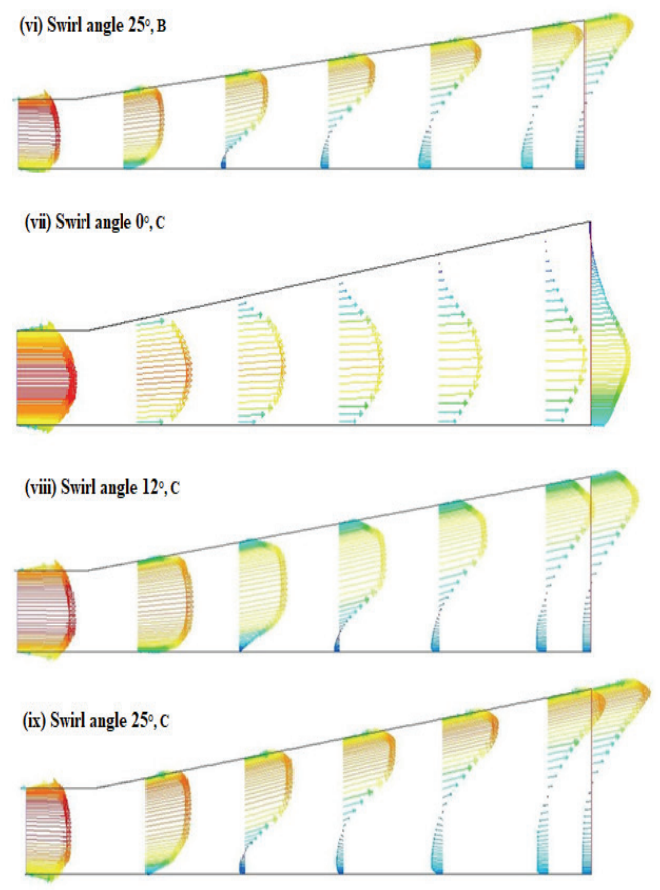

Figure 6. (i-x) Velocity vectors at inlet swirl angles $0^{\circ}, 12^{\circ}$, and $25^{\circ}$ of equivalent cone angle $10^{\circ}, 15^{\circ}$, and $20^{\circ}$.

The uniform flow is distributed between the casing and hub wall at swirl angles $0^{\circ}$ and $12^{\circ}$ as flow moves toward the downward direction in the diffuser $\mathrm{A}$. The flow separation is observed on the inner wall at the inlet swirl angle $25^{\circ}$ along the two-thirds length of diffuser A. In diffuser B, the reverse flow is observed at the swirl angles $12^{\circ}$ and $25^{\circ}$ on the hub walls due to the adverse pressure gradient. The high casing divergent angle in diffuser $\mathrm{C}$ because flow separation is observed on the casing wall with the nonswirling flow. The separation zone's size increases with the inlet swirl angles $\left(12^{\circ}\right.$ and $\left.25^{\circ}\right)$ and results in the shifting of flow separation position and negative velocity towards the hub wall. For the $25^{\circ}$ inlet swirl angle, the flow visualization in the velocity vectors shows that flow is accumulated on the casing wall, and a large separations zone exists on the hub wall. 


\section{Velocity Profile}

The flow behavior and performance of diffuser (A) have been shown in Figures (7-8) in the form of longitudinal velocity profiles and swirl velocity profiles concerning average mass velocity with different inlet swirl conditions, i.e., $0^{\circ}, 12^{\circ}$, and $25^{\circ}$. The hub position represents as $\mathrm{y} / \mathrm{Ym}=0$, and the casing position represents as $\mathrm{y} / \mathrm{Ym}=1$ (Klomp, 1997). The graphs shown in Figures (7-8) are drawn at different location i.e. $\mathrm{x} / \mathrm{L}=0.1,0.3,0.5,0.7$, and 0.9 for diffuser $\mathrm{A}$ of area ratio 3. For no swirl condition, flow is accumulated near the hub wall at an equivalent cone angle of $10^{\circ}$, as shown in Figure 7 (i). The velocities recede at a faster rate on the walls as the continuous diffusion occurs throughout the diffusers. The tangential movement generated by the swirl $12^{\circ}$ is not enough to move the bulk flow from the hub wall to the casing wall, as shown in Figure 7 (ii). Figure 7 (iii) shows a reversal trend for a $25^{\circ}$ swirl in the longitudinal velocity distribution. In this case, bulk flow moves toward the casing wall. The reversal of flow at swirl angle $25^{\circ}$ for $\mathrm{x} / \mathrm{L}=0.5,0.7$ and 0.9 is reversed up to the $\mathrm{y} / \mathrm{Ym}=0.18,0.25$, and 0.27 , respectively. Figure 8 (i-ii) shows swirl velocity distribution at the $12^{\circ}$ and $25^{\circ}$ inlet swirl angles. The trends are similar for $12^{\circ}$ and $25^{\circ}$ swirl angles, but the value of magnitude is different. The bulk flow forced towards the casing in the case of a swirl angle $25^{\circ}$. These trends are based on the conservation of the angular momentum principle. The flow is moving towards the casing wall by introducing a swirl at the inlet.

(i)

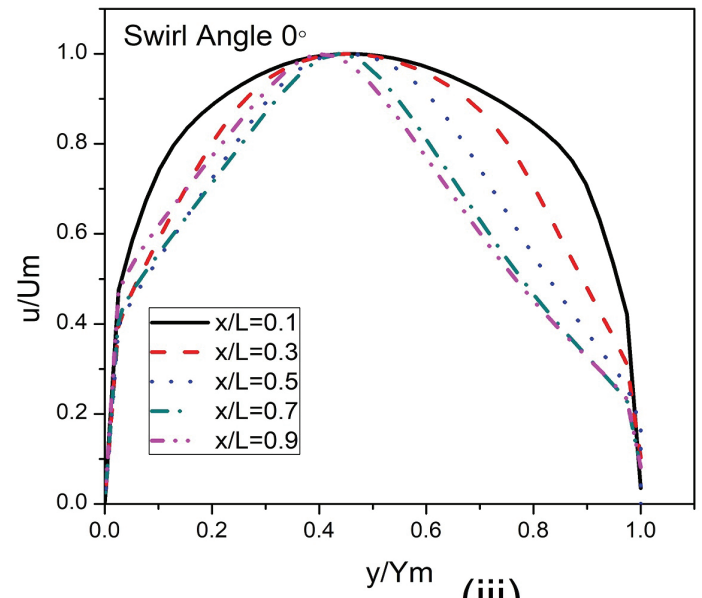

(ii)

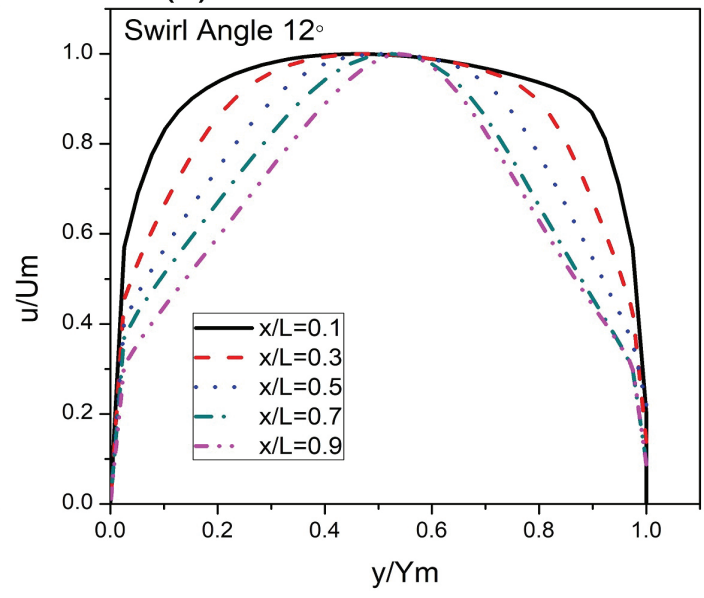

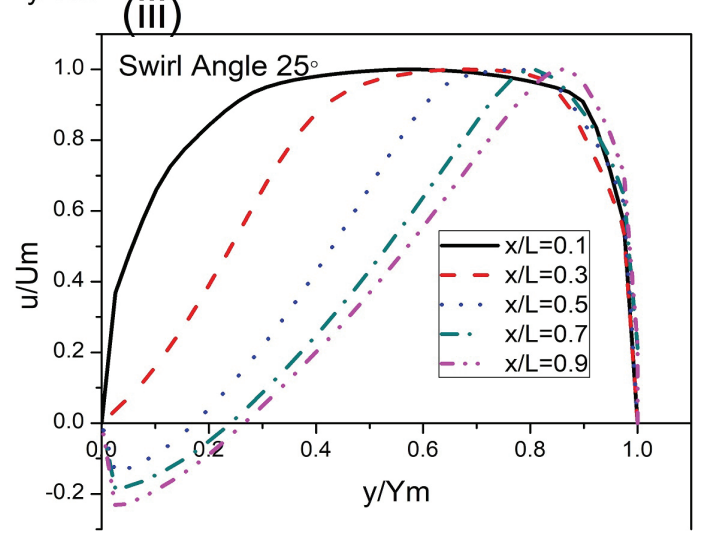

Figure 7. (i-iii) Longitudinal Velocity distribution at inlet swirl angles $0^{\circ}, 12^{\circ}$, and $25^{\circ}$ of equivalent cone angle $10^{\circ}$. 

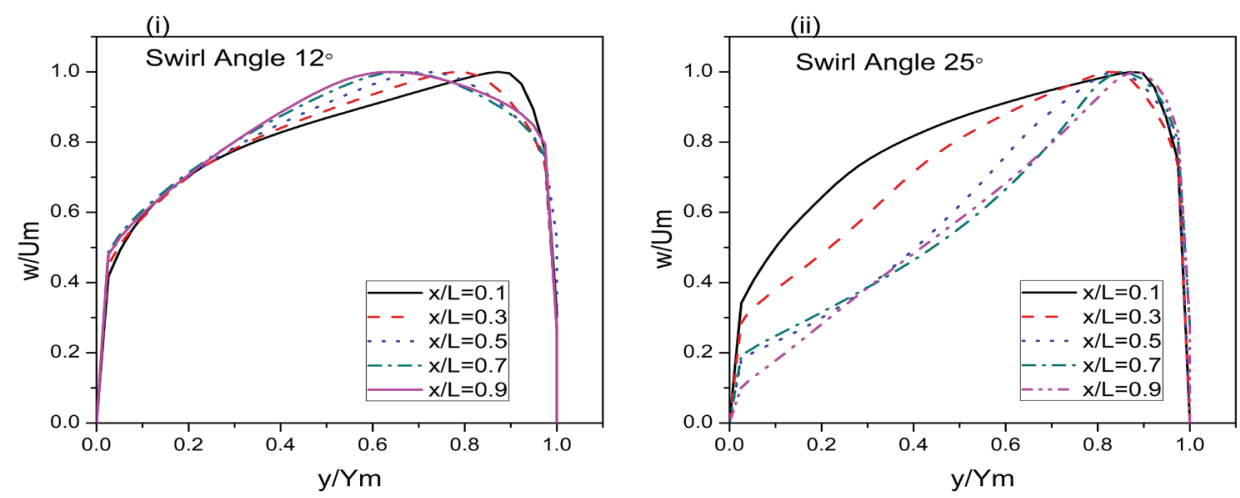

Figure 8. (i-ii) Swirl Velocity distribution at inlet swirl angles $12^{\circ}$ and $25^{\circ}$ of equivalent cone angle $10^{\circ}$.

\section{Pressure Recovery Coefficient}

The coefficient of pressure recovery has been determined in the annular diffuser having equivalent cone angle $10^{\circ}$ with inlet swirl angles $0^{\circ}$ to $25^{\circ}$ at the diffuser's casing wall. The graph is shown in Figure 9 (i) for area ratio 3 with normalized axial length $\mathrm{x} / \mathrm{L}$ (Ibrahim et al. 2007). It can be seen from the plots that $\mathrm{Cp}$ increases with the flow downstream of the diffuser passage. The curves drawn represent the value of $\mathrm{Cp}$ for swirl flow almost identical to the $0^{\circ}$ swirl. The figure shows that marginal $\mathrm{Cp}$ improves with the downstream diffuser passage in the beginning and later on decreases due to separation of flow on the hub as observed from the longitudinal velocity profile distribution. Swirl increases the $\mathrm{Cp}$ at the entrance of the downstream diffuser passage as compared to the non-swirl flow. The highest $\mathrm{Cp}$ is up to $\mathrm{x} / \mathrm{L}=0.18$ at equivalent cone angle $10^{\circ}$ for $25^{\circ}$ inlet swirl angles of the diffuser passage. The Cp plot is shown in Figure 9 (i) shows the maximum improvement of the pressure recovery in an equivalent cone angle of $10^{\circ}$ with a $7.5^{\circ}$ inlet swirl angle. The variation of static pressure recovery coefficient $(\mathrm{Cp})$ with the inlet swirl angle of three types of diffusers (A, B, and C) is shown in Figure 10 (i). These plots indicate that there is a maximum coefficient of static pressure recovery with an inlet swirl angles $7.5^{\circ}$ and $12^{\circ}$ of equivalent cone angles $10^{\circ}$ and $15^{\circ}$, respectively. The pressure recovery increases up to $\mathrm{x} / \mathrm{L}=0.60$ and 0.54 for swirl angles $7.5^{\circ}$ and $12^{\circ}$ respectively of equivalent cone $20^{\circ}$ but later on decreases due to separation of flow and decay swirl intensity. The coefficient of static pressure recovery $(\mathrm{Cp})$ with a variation of the area ratio of diffusers $\mathrm{A}, \mathrm{B}$, and $\mathrm{C}$ along the length is shown in Figure 10 (ii). It is observed from the figure that maximum pressure recovery is obtained from the equivalent cone angle $10^{\circ}$ for an A-type diffuser.
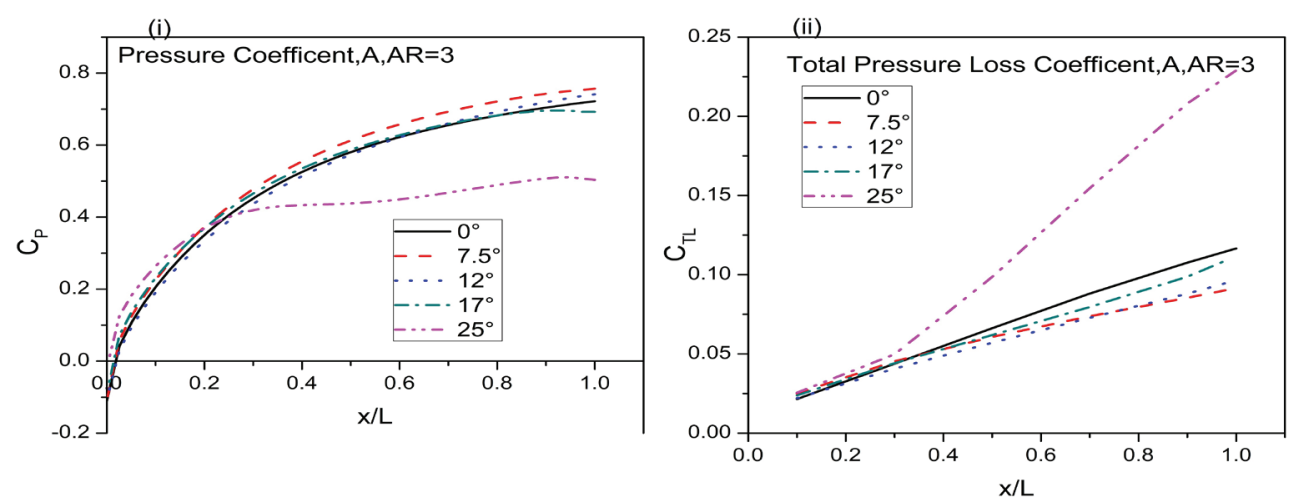

Figure 9. (i) Pressure coefficient at casing of equivalent cone angle $10^{\circ}$.

(ii) Total pressure loss coefficient of equivalent cone angle $10^{\circ}$. 


\section{Total Pressure Loss Coefficient}

The total pressure loss coefficient increases almost linearly across the longitudinal length. As shown in Figure 9 (ii), the $\mathrm{C}_{\mathrm{TL}}$ plot shows the minimum loss coefficient for equivalent cone angle $10^{\circ}$ at $7.5^{\circ}$ inlet swirl angle. This result implies that the inlet swirl angle's optimum selection suppresses the flow separation. The total pressure loss coefficient $\left(\mathrm{C}_{\mathrm{TL}}\right)$ with the swirl angle is shown in Figure 11 (ii). The minimum loss of total pressure coefficient for equivalent cone angle $15^{\circ}$ is up to $12^{\circ}$ swirl angle and gives optimum performance at that angle. It also shows the minimum loss of total pressure coefficient at $7.5^{\circ}$ swirl angle for equivalent cone angle $20^{\circ}$. The maximum loss coefficient is due to the casing's high cant angle, the swirl intensity's decay, and the adverse pressure gradient on the walls.
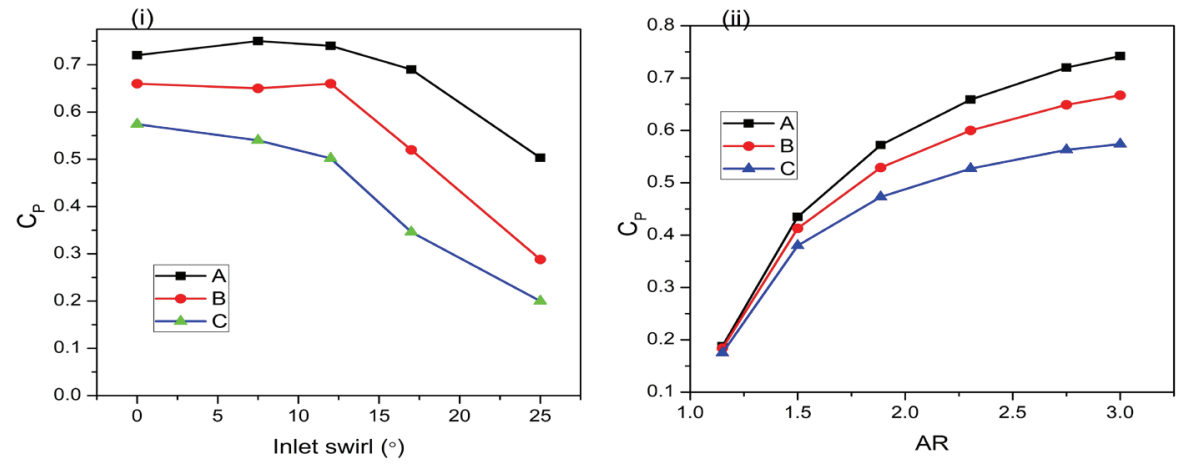

Figure 10. (i) Static pressure recovery coefficient with inlet swirl of diffusers A, B, and C. (ii) Static pressure recovery coefficient $\left(\mathrm{C}_{\mathrm{p}}\right)$ with variation of area ratio of diffusers $\mathrm{A}, \mathrm{B}$, and $\mathrm{C}$ along the length.

\section{Effectiveness}

The diffuser's effectiveness ( $\eta$ ) is plotted about the inlet swirl angle of A, B, and C types diffusers are shown in Figure 20 (i) (Hoadley, 1970). The plots indicate that $\eta$ decreases with increasing equivalent cone angle and the highest value obtained for the A-type diffuser with a swirl angle of $7.5^{\circ}$. The diffuser's effectiveness decreases beyond the swirl angle of $12^{\circ}$ for A and B types diffusers due to the hub's separation and reversal flow. In C type diffuser, the $\eta$ decreases by the swirling flow due to wide space availability, which promotes separation of flow either from the hub or casing wall, as seen in the velocity vector contours of equivalent cone angle $20^{\circ}$.
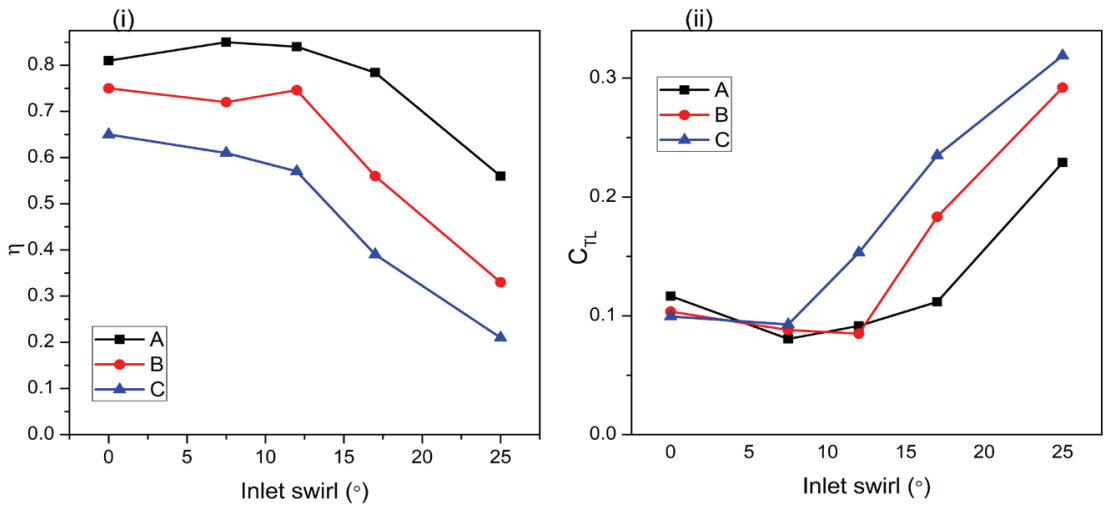

Figure 11. (i) Effectiveness with inlet swirl of diffusers A, B, and C.

(ii) Total pressure loss coefficient with inlet swirl of diffusers A, B, and C. 


\section{CONCLUSION}

The following inferences have been highlighted from the numerical investigation of the incompressible flow through the parallel hub axial annular diffuser having equivalent cone angles $\left(10^{\circ}, 15^{\circ}\right.$, and $\left.20^{\circ}\right)$ and the same area ratio $(\mathrm{AR}=3)$.

1. The longitudinal velocity profile is not symmetrical about the center at any cross-section of diffusers. The diffuser's nonswirling flow is accumulated at the hub, which is shifted towards the casing side with swirl flow.

2. The maximum value of $\mathrm{Cp}$ achieved at the exit of the diffuser is $0.75,0.67$, and 0.56 , corresponding to $7.5^{\circ}, 12^{\circ}$, and $0^{\circ}$ swirl angles and $10^{\circ}, 15^{\circ}$, and $20^{\circ}$ equivalent cone angles, respectively. Hence, it is found that the maximum coefficient of pressure recovery increases up to $75 \%$ at swirl angle $7.5^{\circ}$ of equivalent cone angle $10^{\circ}$ for area ratio 3 .

3. The total pressure loss coefficient $\left(\mathrm{C}_{\mathrm{TL}}\right)$ is minimum at the optimum swirl angle along the diffuser passage. The simulated results show that the optimum swirl angles are $7.5^{\circ}$ and $12^{\circ}$ at equivalent cone angles $10^{\circ}$ and $15^{\circ}$, respectively.

4. The stall is observed on the casing for equivalent cone angle $20^{\circ}$ in nonswirl flow, but it vanishes and moves away from the casing wall with swirl flow.

\section{REFERENCES}

Adenubi, S.O., 1976. Performance and flow regime of annular diffusers with axial turbomachine discharge inlet conditions. J. Fluids Eng., 98(2): 236-242.

Arora, B. B., Pathak, B. D., 2009. Effect of Geometry on the Performance of Annular Diffuser. International Journal of Applied Engineering Research, 5(20): 2639-2652.

Arora, B.B., 2014. Performance analysis of parallel hub diverging casing axial annular diffuser with 20 equivalent cone angle. Australian Journal of Mechanical Engineering, 12(2): 179-194.

Arora, B.B., Kumar, M. and Maji, S., 2010. Analysis of flow separation in wide angle annular diffusers. International Journal of Applied Engineering Research, 5(20): 3419-3428.

Coladipietro, R.M., 1974. Effect of inlet swirl and wall layer thickness on the performance of equiangular annular diffusers. Electronic Theses and Dissertations.

D.W. Bryer, R.C. Pankhurst, 1971. Pressure-Probe Methods for Determining Wind Speed and Flow Direction, HMSO, London.

Hoadley, D., 1970. Three-dimensional turbulent boundary layers in an annular diffuser (Doctoral dissertation, University of Cambridge).

Ibrahim, K.A., Abdalla, H.A., El-Askary, W.A. and Abdel-Salam, A.M., 2007. Numerical study on turbulent swirling flow in annular diffusers. Eng Res Bull, 30(4): 551-69.

Kline, S.J. 1959. On the nature of stall. Journal of basic Engineering, 81(3): 305-319.

Klomp, E.D., 1997. Performance of straight-walled annular diffusers with swirling flow. The Aeronautical Journal, 101(1010): 467-480.

Mohan, R., Singh, S.N. and Agrawal, D.P., 1998. Optimum inlet swirl for annular diffuser performance using CFD. IJEMS, 05 (1):15-21.

Reneau, L.R., Johnston, J.P. and Kline, S.J., 1967. Performance and design of straight, two-dimensional diffusers. J. Basic Eng., 89(1): 141-150.

Sadasivan, S., Arumugam, S.K. and Aggarwal, M.C., 2019. Numerical Simulation of Diffuser of a Gas Turbine using the Actuator Disc Model. Journal of Applied Fluid Mechanics, 12(1): 77-84. 
Shuja, S.Z. and Habib, M.A., 1996. Fluid flow and heat transfer characteristics in axisymmetric annular diffusers. Computers \& fluids, 25(2): 133-150.

Singh, H. and Arora, B.B., 2019. Effect of Area Ratio on Flow Separation in Annular Diffuser. In Advances in Fluid and Thermal Engineering, Springer: 297-305.

Singh, S.N., Agrawal, D.P., Sapre, R.N. and Malhotra, R.C., 1994. Effect of inlet swirl on the performance of wide-angled annular diffusers. IJEMS, 1 (2):63-69.

Singh, S.N., Seshadri, V., Saha, K., Vempati, K.K. and Bharani, S., 2006. Effect of inlet swirl on the performance of annular diffusers having the same equivalent cone angle. Proceedings of the Institution of Mechanical Engineers, Part G: Journal of Aerospace Engineering, 220(2): 129-143.

Ubertini, S. and Desideri, U., 2000. Experimental performance analysis of an annular diffuser with and without struts. Experimental Thermal and Fluid Science, 22(3-4): 183-195. 